\title{
Morphorogical and Structural Studies on Large Spherulites of $\operatorname{Poly}(p$-phenylene terephthalamide)
}

\author{
Duanfu XU, ${ }^{*}$ Kenji OKUYAMA, ${ }^{* *}$ Fumiko Kumamaru, \\ and Motowo TAKAYANAGI \\ Department of Applied Chemistry, Faculty of Engineering, \\ Kyushu University 36, Hakozaki, Higashi-ku, Fukuoka 812, Japan
}

(Received September 16, 1983)

\begin{abstract}
The poly( $p$-phenylene terephthalamide) (PPTA) spherulite grown from a concentrated sulfuric acid solution and its hydrolysis products were investigated by electron microscopy and X-ray diffraction. Sharp Bragg reflections and their spacings indicated that the nascent spherulite consists of complex crystals of PPTA and sulfuric acid. All the diffraction spots from the hydrolysis products of PPTA/ $\mathrm{H}_{2} \mathrm{SO}_{4}$ spherulites could be associated with the Form II crystal with one exception on the equator. This exceptional spot had a fairy strong intensity in the diffraction patterns from air-dried spherulites and was assigned to the (100) reflection. On the other hand, the intensity of this reflection could not be expected from the packing arrangement of the Form II crystal. To explain the intensity of (100), the Form II crystal structure was modified and water was introduced into the unit cell. The structure found showed good agreement between observed and calculated structure amplitudes. Further, the calculated amount of bound water was almost the same as that lost by annealing above $400 \mathrm{~K}$.
\end{abstract}

KEY WORDS Aromatic Polyamide / Poly ( $p$-phenylene terephthalamide) Spherulite / Crystal Structure / X-Ray Diffraction / SEM Observation / TEM Observation /

The poly ( $p$-phenylene terephthalamide) (PPTA) molecule, whose chemical repeating unit is shown in Figure 1 along with the atomic numbering, is typically rigid. Its fiber has good thermal stability, ultrahigh modulus and strength. To elucidate the nature of these physical properties, many structural and morphological studies have been made. Some of these have dealt with the spherulites of PPTA grown from a concentrated sulfuric acid solution. ${ }^{1-6}$ X-Ray diffraction data ${ }^{1,6}$ indicated that these spherulites consist of molecular complex crystals of poly ( $p$-phenylene terephthalamide) and sulfuric acid (hereafter, designated as $\mathrm{PPTA} / \mathrm{H}_{2} \mathrm{SO}_{4}$ spherulites).

In our previous paper, ${ }^{7}$ we investigated the molecular orientation in the PPTA spherulite following treatment with water, and found it to have the Form II crystal structure ${ }^{13}$ and that its molecular axis is oriented in the radial direction of the spherulite. In this study, the PPTA $/ \mathrm{H}_{2} \mathrm{SO}_{4}$ complex spherulite and its hydrolysis products were investigated by morphological observation and X-ray diffraction. The Form II crystal structure of PPTA was modified to explain the strong intensity of the (100) reflection from air-dried spherulites.

\section{EXPERIMENTAL}

\section{Sample Preparation}

Dry PPTA $([\eta]=3.82)$ was dissolved in $100 \%$ sulfulic acid at $40-45^{\circ} \mathrm{C}$. The con-

* On leave from the Institute of Chemistry, The Chinese Academy of Sciences.

** Present address: Department of Polymer Engineering, Tokyo University of Agriculture and Technology, Koganei, Tokyo 184, Japan. 
D. XU et al.

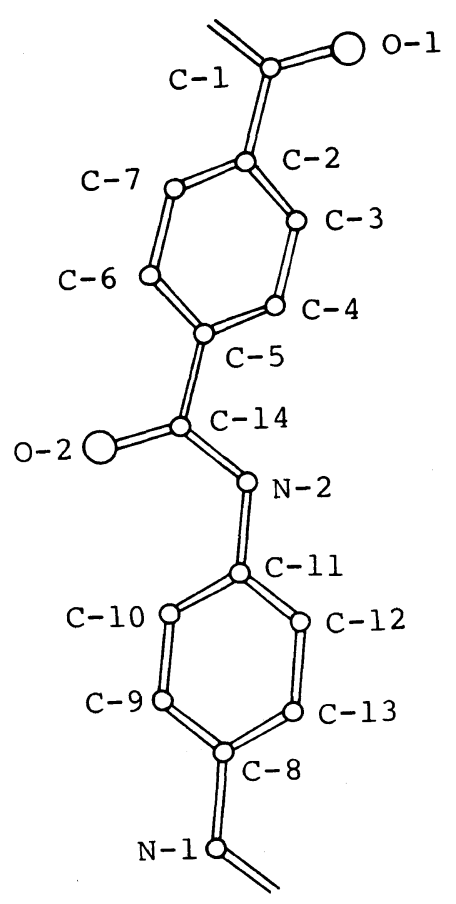

Figure 1. The chemical repeating unit of poly( $p$ phenylene terephthalamide) and the atomic labeling.

centration of the polymer was $12 \mathrm{wt} \%$. The solution was cooled to room temperature and sealed in a test tube or ampoule after filtration. The crystallization of the solution was carried out at room temperature (about $20-28^{\circ} \mathrm{C}$ ).

\section{$X$-Ray Diffraction}

Samples of PPTA/ $\mathrm{H}_{2} \mathrm{SO}_{4}$ complex spherulites and their hydrolysis products were sliced along the diameter and sealed in a sample chamber with a thin mica window on each side. Diffraction patterns were recorded on a film in a Searle Toroid Camera filled with helium, using Ni-filtered $\mathrm{Cu} K_{\alpha}$ radiation of $0.1542 \mathrm{~nm}$ wavelength. Microbeam X-ray diffraction patterns were recorded using a flatplate camera with $\mathrm{Cu} K_{\alpha}$ microbeam ( $30 \mu \mathrm{m}$ in diameter) from a microfocus generator (Rigaku, Microflex). The diffraction patterns were traced radially with a Joyce Loebl MK III microdensitometer.

\section{Electron Microscopy}

The PPTA $/ \mathrm{H}_{2} \mathrm{SO}_{4}$ complex spherulites were first washed with diluted sulfuric acid and then with water. The water-washed spherulites (hereafter called PPTA $/ \mathrm{H}_{2} \mathrm{O}$ spherulites) were frozen in liquid nitrogen and broken. After being dried in air, the freeze fracture surfaces were coated with gold and their morphology was observed by a Hitachi S-430 Scanning electron microscope.

A Hitachi H-500 Transmission electron microscope was used to study the morphology and structure of PPTA spherulites. Slices of the PPTA $/ \mathrm{H}_{2} \mathrm{O}$ spherulites were fragmented by ultrasonic irradiation in water for $2 \mathrm{~h}$. A drop of the suspension was deposited on a carbon-coated electron microscope grid. After the water was evaporated, the samples were used for both morphological observation and selected area electron diffraction measurement.

\section{RESULTS AND DISCUSSION}

Crystal Growth and Structure of PPTA/ $\mathrm{H}_{2} \mathrm{SO}_{4}$

\section{Complex Spherulites}

The phase diagram of PPTA $/ \mathrm{H}_{2} \mathrm{SO}_{4}$ systems has been studied by many researchers. ${ }^{8-11}$ However, the reported crystal-liquid crystal phase transition curves are not consistent with one another. A matter not discussed so far. We observed that large spherulites, about $10 \mathrm{~mm}$ in diameter, readily grew from a sulfuric acid solution when the solution was maintained long in the liquid crystalline phase close to the transition point. During the crystallization, nuclei appeared sporadically after an induction period, followed by slow spherulite growth. The diameter of the spherulites kept increasing over a period of several months. A typical growth curve of PPTA/ $\mathrm{H}_{2} \mathrm{SO}_{4}$ complex spherulites from a sulfuric acid solution is shown in Figure 2.12 The crystallization of PPTA liquid crystal shows that the "liquid crystalline state" of the PPTA solution is thermodynamically unstable and supersatu- 
rated, taking several months to come to an equilibrium state. Therefore, no exact measurement of the liquid crystal-crystal transition curve of PPTA/ $\mathrm{H}_{2} \mathrm{SO}_{4}$ system was feasible. This is probably one reason for the inconsistency of the reported transition curves.

Figure 3 shows the microdensitometer tracing of the X-ray diffraction pattern from

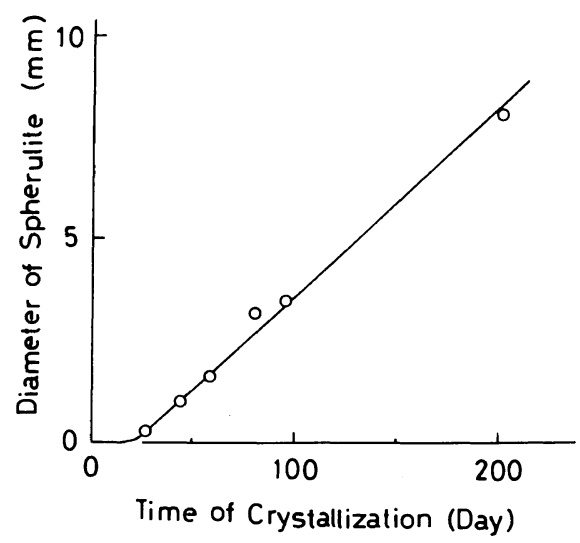

Figure 2. Growth curve of a PPTA/ $\mathrm{H}_{2} \mathrm{SO}_{4}$ complex spherulite from a sulfuric acid solution $(12 \mathrm{wt} \%$, at room temperature). the PPTA/ $\mathrm{H}_{2} \mathrm{SO}_{4}$ complex spherulite. The pattern is remarkably sharp. The half-widths of the reflection profiles are as narrow as that of the (111) reflection of silicon single crystals. The crystallite sizes are apparently much larger than those of usual semicrystalline polymers. In addition to the very sharp Bragg reflections, an amorphous halo is seen in the X-ray pattern (Figure 3), which indicates that the space between crystallites was permeated with the sulfuric acid solution of PPTA. The Bragg spacings for respective reflection are listed in Table I, along with those obtained by other researchers. ${ }^{1,6} \mathrm{~A}$ comparison with the data of Arpin et al. ${ }^{6}$ indicates that our large spherulites consist of the two complex crystals designated by those authors as $\mathrm{C}_{1}$ and $\mathrm{C}_{2}$ solvates.

\section{SEM and TEM Observation of Hydrolysis} Products of the PPTA $/ \mathrm{H}_{2} \mathrm{SO}_{4}$ Spherulites

For morphological observation and structural study, the PPTA/ $\mathrm{H}_{2} \mathrm{SO}_{4}$ complex spherulites were washed with water, this may decompose the crystallites in these spherulites.

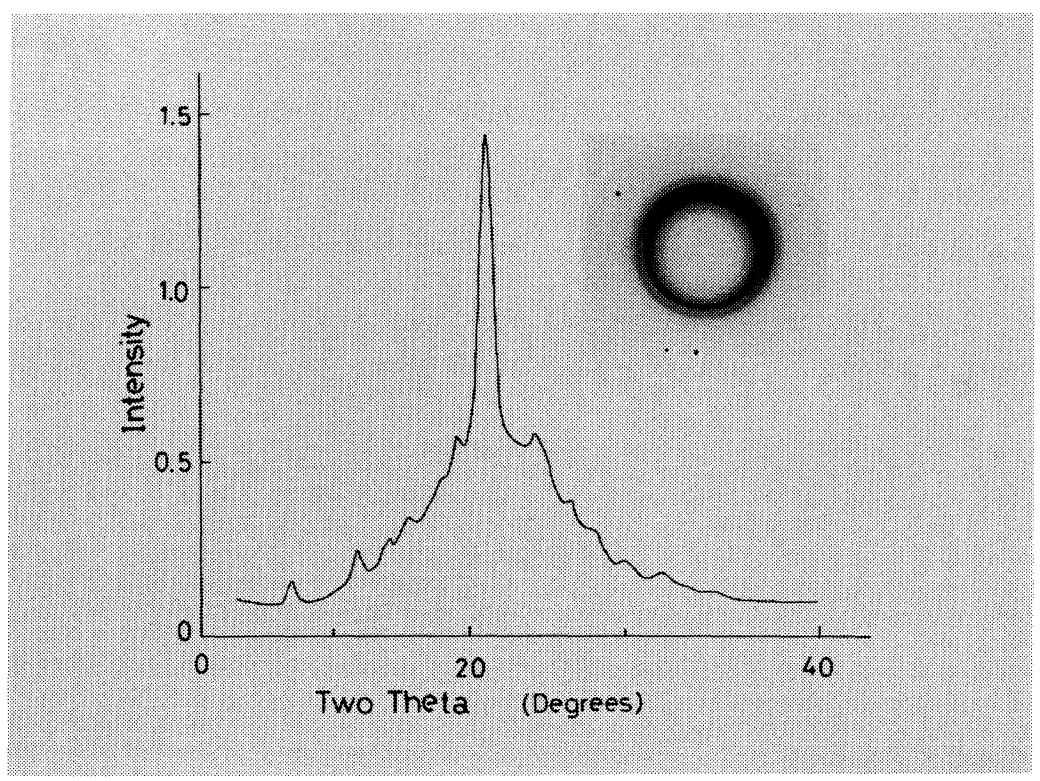

Figure 3. A radial microdensitometer tracing of the X-ray diffraction pattern of the PPTA/ $\mathrm{H}_{2} \mathrm{SO}_{4}$ complex spherulite and its original diffraction pattern. 
Table I. Comparison of Bragg spacings for PPTA/ $\mathrm{H}_{2} \mathrm{SO}_{4}$ complex spherulites with those studied by other researchers

\begin{tabular}{|c|c|c|c|}
\hline \multirow{2}{*}{ This work } & \multirow{2}{*}{$\begin{array}{l}\text { Iovleva } \\
\text { et al. }\end{array}$} & \multicolumn{2}{|c|}{ Arpin et al..$^{6}$} \\
\hline & & $\mathrm{C}_{1}$ & $\mathrm{C}_{2}$ \\
\hline $1.212 \mathrm{~nm}$ & $1.190 \mathrm{~nm}$ & $1.181 \mathrm{~nm}$ & $-\mathrm{nm}$ \\
\hline 0.720 & 0.720 & 0.716 & - \\
\hline 0.599 & 0.615 & - & 0.608 \\
\hline 0.545 & 0.540 & 0.541 & - \\
\hline- & - & - & 0.510 \\
\hline 0.479 & 0.490 & - & 0.479 \\
\hline 0.451 & - & 0.449 & - \\
\hline \multirow[t]{2}{*}{0.409 (double) } & 0.415 & 0.413 & - \\
\hline & & 0.402 & 0.393 \\
\hline 0.361 & 0.372 & - & 0.371 \\
\hline 0.350 & 0.350 & 0.350 & 0.350 \\
\hline- & - & 0.342 & - \\
\hline 0.330 & 0.329 & 0.328 & - \\
\hline 0.314 & 0.312 & 0.307 & - \\
\hline 0.297 & 0.294 & - & - \\
\hline 0.277 & 0.277 & - & - \\
\hline 0.257 & 0.254 & - & - \\
\hline
\end{tabular}

Therefore, what was observed under the electron microscope and by $\mathrm{X}$-ray diffraction measurement must have been the morphology and structure of the hydrolysis products of PPTA/ $/ \mathrm{H}_{2} \mathrm{SO}_{4}$ complexes rather than those of intact spherulites. Nevertheless, a study of these hydrolysis products should provide a better understanding of the structure of PPTA and the crystallization process of Aramid fibers.

The SEM photograph of the broken hemisphere of the PPTA/ $\mathrm{H}_{2} \mathrm{O}$ spherulite is shown in Figure 4(a) which clearly shows a skin and core structure divided by a crevice in the lower fragment in the photograph. A rough fracture surface and smooth cutting surface can also be seen. The enlarged photograph of the skin structure (Figure 4(b)) reveals a number of cavities. Microbeam X-ray diffraction patterns indicated that the orientation of PPTA molecules is random in the skin part. ${ }^{7}$ Figure 4(c) shows the annular nucleus (about $50 \mu \mathrm{m}$ in diameter) of a spherulite and that it consists of many fibrous structural units of several mi- crometers in diameter. Further, smaller fibrous units about $100 \mathrm{~nm}$ wide were observed on the surface of the fibrous units. A detailed structure of the fracture surface marked by the arrow in Figure 4(a) is shown enlarged in Figure 4(d), which indicates that fibrous units about $200 \mathrm{~nm}$ wide, on the average, orient in the radial direction of the spherulite.

Figure 5 shows a TEM photograph of a fibril torn from a slice of a spherulite by ultrasonic irradiation in water. From its width, this fibril may be assumed to be one of those in Figure 4(d). The electron diffraction from the encircled area indicates that the molecular axis of the PPTA lies along the fibril and that this is a typical diffraction pattern of Form II crystals. In many cases, however, diffraction patterns were mixtures of those from Form I and II. Since the transition of Form II to I takes place by annealing, ${ }^{13}$ it seems that Form II crystals partially change to Form I by elevated temperature during the observation.

\section{$X$-Ray Diffraction of Hydrolysis Products of the PPTA/ $\mathrm{H}_{2} \mathrm{SO}_{4}$ Spherulites}

The microdensitometer tracing curves of $\mathrm{X}$ ray diffraction patterns from the hydrolysis products of $\mathrm{PPTA} / \mathrm{H}_{2} \mathrm{SO}_{4}$ spherulites are shown in Figure 6. Here, $\mathrm{A}$ and $\mathrm{B}$ are the diffraction curves before and after drying in air at room temperature, respectively, for one day. The wide angle X-ray diffraction (WAXD) curves of these hydrolysis products revealed that the crystallinities of both samples were rather low. Only a few diffuse diffractions appeared in the WAXD curves with maxima corresponding to the Bragg spacings of 0.77 , $0.51,0.39$, and $0.33 \mathrm{~nm}$. The Bragg spacings of air-dried PPTA spherulites were similar to those of PPTA $/ \mathrm{H}_{2} \mathrm{O}$ spherulites. However, the widths of these reflections were narrower than those of PPTA/ $\mathrm{H}_{2} \mathrm{O}$ spherulites. The intensity distribution differed greatly in these two samples; this is associated with scattering from the amorphous water in the system. 

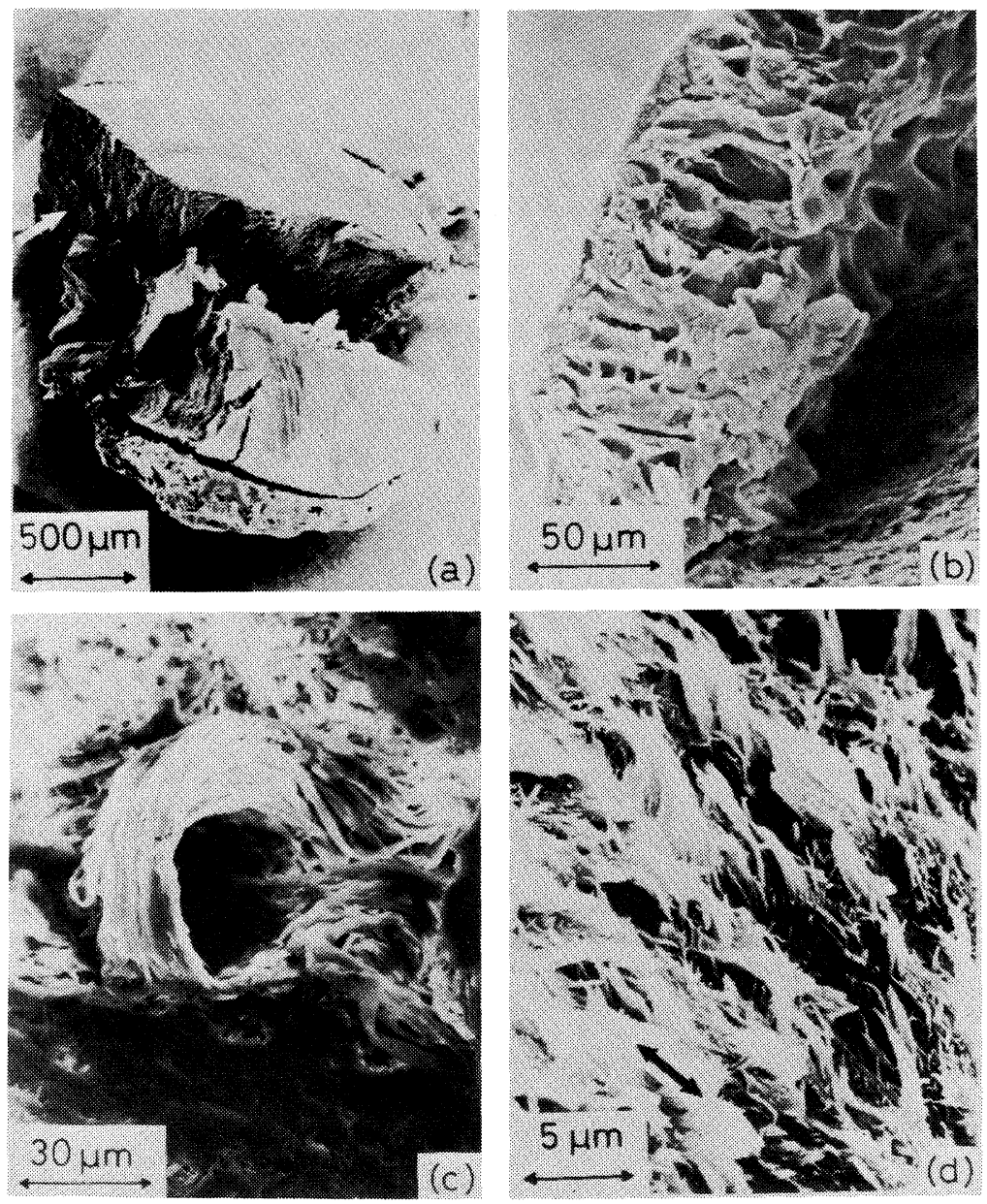

Figure 4. Scanning electron micrographs of the freeze fracture of a large PPTA spherulite. (a) Broken hemisphere; the smooth and rough parts correspond to the cutting and fracture surfaces, respectively. In the lower fragment, a skin and core structure can be seen. (b) Enlargement of the skin structure showing many cavities. (c) The annular nucleus consists of many fibrous structure units with several micrometers in diameter. (d) A detailed structure of the fracture surface marked by an arrow in (a). The arrow indicates the radial direction of the spherulite.

Thus, for the PPTA/ $\mathrm{H}_{2} \mathrm{O}$ spherulites the atomic scattering factors were apparently deformed by the amorphous water in the system, ${ }^{16}$ particularly in the region of $\sin \theta / \lambda<$ 0.25 . The WAXD results on PPTA/ $\mathrm{H}_{2} \mathrm{O}$ and air-dried PPTA spherulites are compared in Table II. The diffraction data indicate that the crystal structures of these samples basically correspond to the Form II crystals proposed by Haraguchi et al. ${ }^{13}$ However, it should be pointed out that an extra diffraction with a spacing of $0.77 \mathrm{~nm}$ in both curves was observed. This reflection was indexed as (100) of the Form II crystal. Hancock et al. ${ }^{17}$ also found a reflection of $0.759 \mathrm{~nm}$ in the diffraction patterns from wet-spun fibers and original Kevlar fibers. They, however, attributed this to the reflection from some impurity. The crystal size of air-dried PPTA spherulites, roughly estimated by the widths of the reflec- 


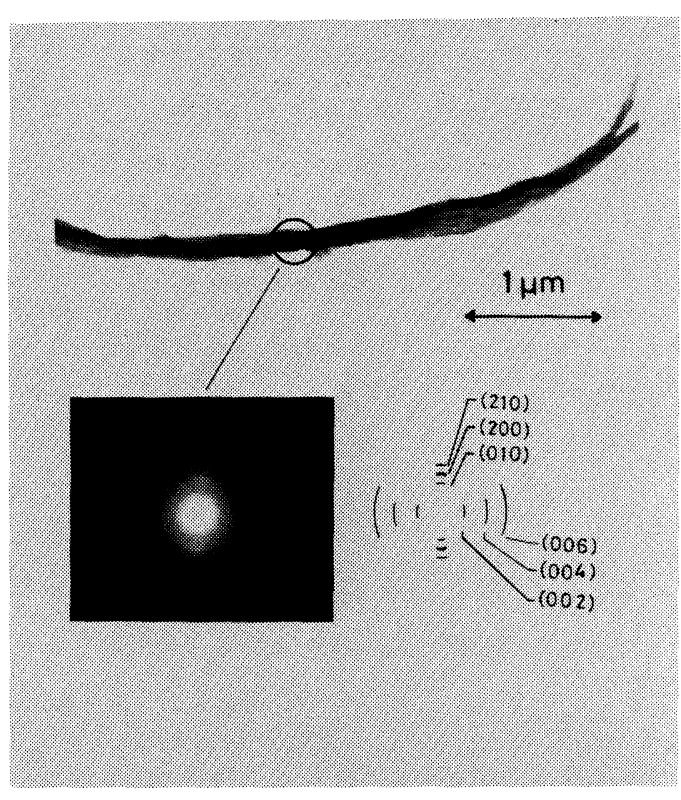

Figure 5. Transmission electron micrograph of a PPTA fibril and an electron diffraction diagram from the encircled area along with its schematic diagram.

tions and Scherrer equation, is only $2-3 \mathrm{~nm}$, indicating that the thickness of the ordered domains in these samples is only 4-6 times larger than the lattice dimensions.

A typical microbeam diffraction pattern of an air-dried PPTA large spherulite is shown in Figure 7, along with its schematic diagram. As has been shown, ${ }^{7}$ the microbeam X-ray diffraction patterns from various parts of the PPTA $/ \mathrm{H}_{2} \mathrm{O}$ spherulite indicated that the molecular axis orients in the radial direction of the spherulite. The observed reflections were characterized by diffuse equatorial reflections and a sharp meridional reflection (004), and indicated the system to consist of well-oriented molecules but of a very limited lateral ordering. Based on the cell dimensions of Form II crystals, the three equatorial reflections of $0.50,0.39$ and $0.32 \mathrm{~nm}$ spacings were indexed as (010), (200), and (210), respective1y. Usually, the diffuse (210) reflection could not be discriminated from the sharp (004) reflection in powder diffraction patterns because

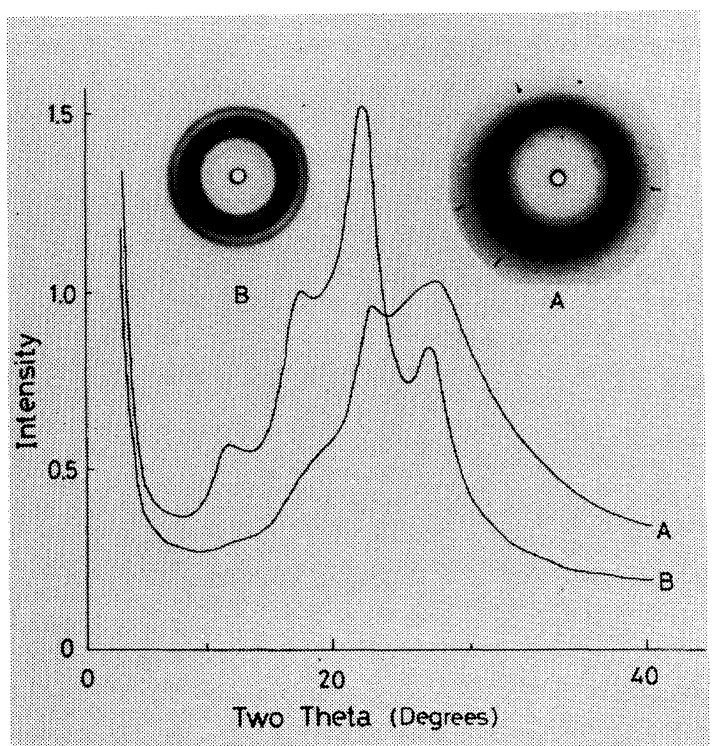

Figure 6. Radial microdensitometer tracings of the Xray diffraction patterns of the hydrolysis products of PPTA/ $\mathrm{H}_{2} \mathrm{SO}_{4}$ complex spherulites and their original diffraction patterns. A, PPTA/ $\mathrm{H}_{2} \mathrm{O}$ spherulite; $\mathrm{B}$, same sample as A except for being dried in air at room temperature for one day.

Table II. WAXD spacings and intensities for the hydrolysis products of PPTA/ $\mathrm{H}_{2} \mathrm{SO}_{4}$ spherulites

\begin{tabular}{|c|c|c|c|c|}
\hline \multirow{2}{*}{ Index } & \multicolumn{2}{|c|}{$\begin{array}{l}\mathrm{PPTA} / \mathrm{H}_{2} \mathrm{O} \\
\text { spherulite }\end{array}$} & \multicolumn{2}{|c|}{$\begin{array}{l}\text { Air-dried PPTA } \\
\text { spherulite }\end{array}$} \\
\hline & Spacing & Intensity & Spacing & Intensity \\
\hline 100 & $0.766 \mathrm{~nm}$ & 3 & $0.766 \mathrm{~nm}$ & 18 \\
\hline $\begin{array}{lll}0 & 1 & 0\end{array}$ & 0.508 & 35 & 0.516 & 55 \\
\hline 200 & 0.393 & 100 & 0.400 & 100 \\
\hline $\left.\begin{array}{lll}2 & 1 & 0 \\
0 & 0 & 4\end{array}\right\}$ & 0.325 & 110 & 0.327 & 47 \\
\hline
\end{tabular}

of their similar spacings. In the diffraction pattern from a well-oriented sample (Figure 7), however, these two reflections were clearly separated. The diffuse diffraction with $0.32 \mathrm{~nm}$ spacing in Figure 6 is considered to be the (210) reflection rather than the (004) reflection.

\section{Structural Model for Hydrolysis Products of $\mathrm{PPTA} / \mathrm{H}_{2} \mathrm{SO}_{4}$ Spherulites}

All the spacings of the diffraction peaks in 

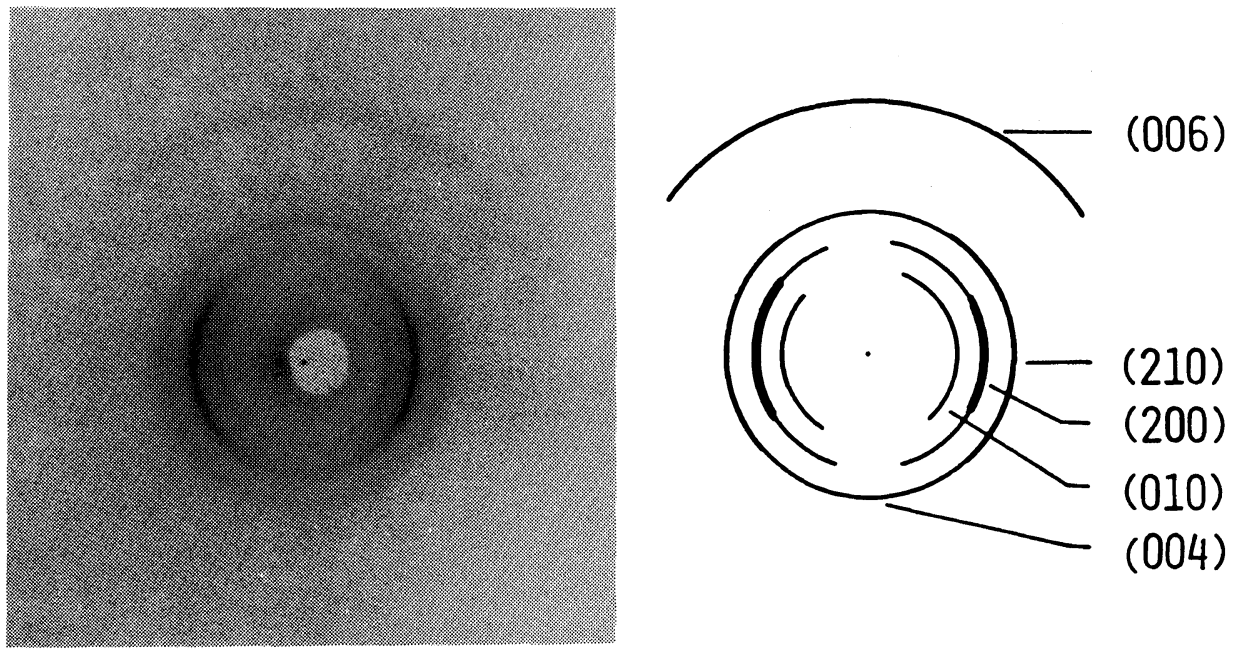

Figure 7. Microbeam X-ray diffraction pattern of an air-dried PPTA spherulite along with its schematic diagram.

the X-ray patterns from the hydrolysis product of PPTA $/ \mathrm{H}_{2} \mathrm{SO}_{4}$ spherulite and its air-dried sample (Figure 6 and Table II) were indexed on the basis of the unit cell of Form II crystal, as has already been shown. According to Haraguchi's explanation, ${ }^{13}$ the unit cell of a Form II crystal contains two molecules at the positions $(u=0.0 a, v=0.0 b)$ and $(u=0.5 a$, $v=0.0 b$ ) and aligned with the amide planes parallel to the $b c$-plane to form hydrogenbonded sheets.

To interpret the clear (100) reflection in the diffraction from air-drid PPTA (Figure 6), various structural models were examined using the LALS (linked-atom least-squares) program. ${ }^{18}$ In doing so, the molecular conformation was held to that of Northolt ${ }^{14}$ and only the orientation angles $\left(\mu_{1}\right.$ and $\left.\mu_{2}\right)$ about the molecular axes of two PPTA molecules and the positioning parameters $\left(u_{2}\right.$ and $\left.w_{2}\right)$ of the second molecules were varied together with three additional parameters for each water molecule. Structures were refined to minimize the contact energy between non-bonded atoms and obtain better agreement between observed and calculated structure amplitudes. For the latter purpose, the intensities obtained from

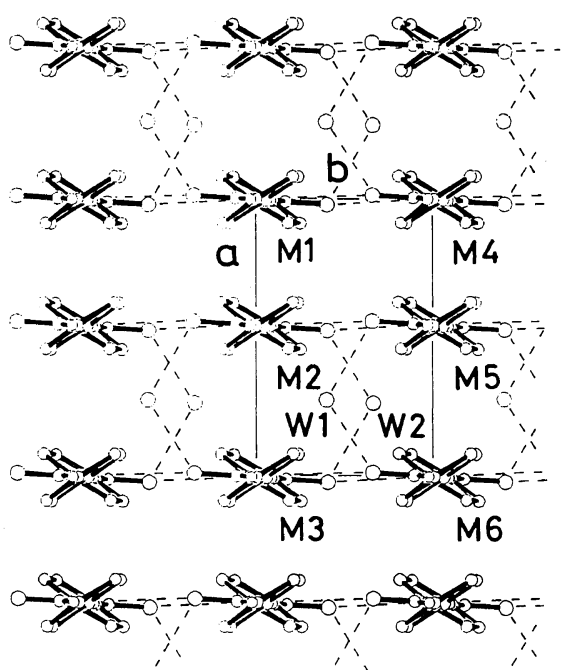

Figure 8. Proposed structural model for a modified Form II crystal projected along the $z$-axis. Dotted lines indicate hydrogen bonds. The drawing was made using an ORTEP computing program (19).

the diffraction pattern of air-dried PPTA (Figure 6, curve B) were used.

Only when water molecules were introduced into one side of the PPTA sheet did the (100) reflection have some intensity. The most plau- 


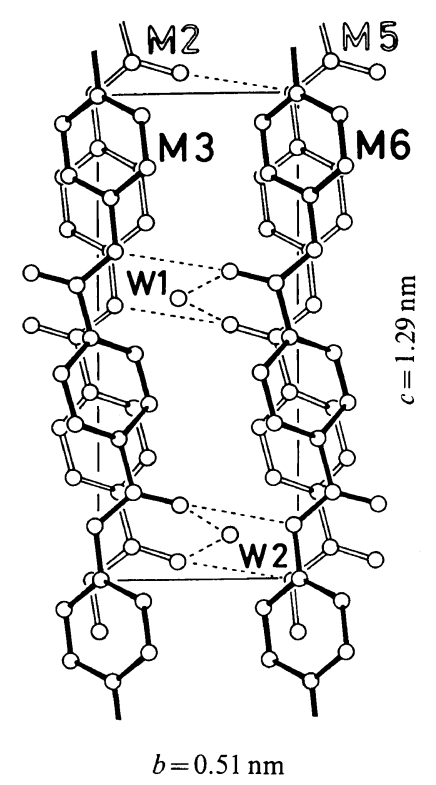

Figure 9. Proposed structural model for a modified Form II crystal projected along the $a$-axis.

sible structure is shown in Figures 8 and 9, and the atomic coordinates are listed in Table III. The calculated structure amplitudes are given in Table IV, along with those observed for the air-dried PPTA spherulite. In this structure, the unit cell contains statistically two water molecules with half occupancies linking the adjacent sheets by a water bridge, $\mathrm{C}=\mathrm{O}$ (M5 or $\mathrm{M} 2$ in Figure 8$)-\left(\mathrm{H}_{2} \mathrm{O}\right)-\mathrm{O}=\mathrm{C}(\mathrm{M} 6$ or M3). Judging from the low crystallinity and half occupancies at each location, various types of unit cells are conceivable. Some unit cells may have two or one water molecule, while others may have no water at the positions shown in Figures 8 and 9. Therefore, the actual structure in the hydrated PPTA spherulite should be a mixture of the various types of structures mentioned above.

When the hydrated PPTA spherulites were dried under severe conditions, water was removed and hence the (100) reflection ceased to appear. This was also the case for the diffraction patterns from the annealed PPTA films coagulated with water. ${ }^{13}$ Only when the PPTA
Table III. Fractional positions of atoms for the modified Form II structure model

\begin{tabular}{|c|c|c|c|}
\hline Atom & $\mathrm{X}$ & $\mathrm{Y}$ & Z \\
\hline O-1 & -0.015 & -0.345 & 0.633 \\
\hline $\mathrm{O}-2$ & 0.019 & 0.402 & 0.153 \\
\hline $\mathrm{N}-1$ & 0.004 & 0.085 & 0.676 \\
\hline $\mathrm{N}-2$ & -0.001 & -0.028 & 0.110 \\
\hline C-1 & -0.005 & -0.112 & 0.608 \\
\hline $\mathrm{C}-2$ & -0.002 & -0.040 & 0.497 \\
\hline C-3 & 0.084 & 0.183 & 0.465 \\
\hline C-4 & 0.087 & 0.251 & 0.361 \\
\hline C-5 & 0.005 & 0.097 & 0.287 \\
\hline C-6 & -0.080 & -0.126 & 0.321 \\
\hline C-7 & -0.084 & -0.194 & 0.425 \\
\hline C-8 & 0.003 & 0.057 & 0.786 \\
\hline C-9 & 0.086 & -0.151 & 0.832 \\
\hline C- 10 & 0.084 & -0.180 & 0.939 \\
\hline C-11 & 0.000 & 0.000 & 1.000 \\
\hline C-12 & -0.083 & 0.208 & 0.954 \\
\hline C-13 & -0.081 & 0.237 & 0.847 \\
\hline C-14 & 0.008 & 0.169 & 0.178 \\
\hline $\mathrm{H}-1$ & 0.012 & 0.264 & 0.645 \\
\hline H-2 & -0.009 & -0.207 & 0.141 \\
\hline Phenylene & 0.146 & -0.333 & 0.972 \\
\hline \multirow[t]{7}{*}{ Hydrogens } & 0.147 & -0.284 & 0.787 \\
\hline & -0.144 & 0.341 & 0.999 \\
\hline & -0.143 & 0.390 & 0.814 \\
\hline & -0.146 & -0.357 & 0.448 \\
\hline & -0.141 & -0.239 & 0.268 \\
\hline & 0.145 & 0.296 & 0.518 \\
\hline & 0.149 & 0.414 & 0.338 \\
\hline OW1 & 0.721 & 0.395 & 0.582 \\
\hline OW2 & 0.734 & 0.659 & 0.096 \\
\hline
\end{tabular}

Atomic coordinates $\left(\mathrm{X}^{\prime}, \mathrm{Y}^{\prime}, \mathrm{Z}^{\prime}\right)$ for the second molecule are deduced by the following relations from the above coordinates $(X, Y, Z)$.

$\mathrm{X}^{\prime}=\mathrm{X}+0.4533, \mathrm{Y}^{\prime}=\mathrm{Y}, \mathrm{Z}^{\prime}=\mathrm{Z}+0.8875$.

samples were treated by moderate drying, as in the case of films swollen with water, ${ }^{13}$ the asspun, hot-drawn and Kevlar fiber, ${ }^{17}$ and the hydrolysis products of PPTA/ $\mathrm{H}_{2} \mathrm{SO}_{4}$ spherulites in this study, did the (100) reflection appear at various intensities depending on the water content and periodicity. By elemental analysis of the PPTA films before and after the annealing, Haraguchi ${ }^{13}$ found that the water content of $3-4 \mathrm{wt} \%$ ( 0.5 water molecules per one chemical repeating unit of PPTA) could be removed by annealing. He also found some 
Table IV. Observed and calculated structure amplitudes for the modified Form II crystal

\begin{tabular}{rrrrr}
$h$ & $k$ & $l$ & $\left|F_{\text {obs }}\right|$ & $\left|F_{\text {calc }}\right|$ \\
\hline 0 & 0 & 1 & - & 2 \\
1 & 0 & 0 & 42 & 31 \\
1 & 0 & 1 & - & 1 \\
0 & 0 & 2 & - & 1 \\
0 & 1 & 0 & 73 & 73 \\
1 & 0 & 2 & - & 6 \\
0 & 1 & 1 & - & 10 \\
1 & 1 & 0 & - & 18 \\
0 & 0 & 3 & - & 1 \\
1 & 1 & 1 & - & 8 \\
2 & 0 & 0 & 98 & 105 \\
0 & 1 & 2 & - & 13 \\
2 & 0 & 1 & - & 1 \\
1 & 0 & 3 & - & 5 \\
1 & 1 & 2 & - & 13 \\
2 & 0 & 2 & - & 4 \\
0 & 1 & 3 & - & 47 \\
0 & 0 & 4 & 67 & \\
2 & 1 & 0
\end{tabular}$\quad \sqrt{ }$

absorption bands which may be assigned to the $\mathrm{O}-\mathrm{H}$ stretching vibration of the bound water disappearing by annealing at temperatures above $400 \mathrm{~K} .{ }^{13}$ These findings agree very well with our modified Form II crystal structure proposed above.

\section{Speculation on the Formation of PPTA Form II Crystals}

The morphorogical features of PPTA/ $\mathrm{H}_{2} \mathrm{O}$ spherulites may be interpreted in terms of a diffusion controlled hydrolysis process of PPTA $/ \mathrm{H}_{2} \mathrm{SO}_{4}$ complex spherulites. The hydrolysis of the PPTA/ $\mathrm{H}_{2} \mathrm{SO}_{4}$ crystals starts at the surface of each crystal. As the sulfuric acid of the complex crystal combines with water, the PPTA/ $\mathrm{H}_{2} \mathrm{SO}_{4}$ complexes are decomposed and a hydrogen-bonded PPTA molecular layer is formed on the surface of the crystal. This hydrolysis takes place layer by layer as water diffuses toward the center of the crystal. The oriented nascent PPTA molecular layers stack up layer by layer. However, this process takes place so rapidly that the layers connot stack regularly into a three-dimensional ordered lattices, so that only very small ordered domains (about a few molecular layers) are formed. These domains are considered to be the basic structural units of the microfibrils. As water diffuses continueously toward the center of the spherulite, new nascent microfibrils are formed successively, leaving many microcavities between the microfibrils. The appearance of hydrolysis products still resembles that of an intract PPTA $/ \mathrm{H}_{2} \mathrm{SO}_{4}$ complex crystal. The so called swollen state of PPTA/ $\mathrm{H}_{2} \mathrm{O}$ spherulite is an aggregate of PPTA microfibrils interdispersed with water instead of a usual swollen polymer.

When PPTA $/ \mathrm{H}_{2} \mathrm{O}$ spherulites are dried in air, various structures considered in the previous section appear. From the results of $\mathrm{X}$ ray diffraction, however, the structure with the asymmetrically located water molecules is considered most plausible. Under severer drying conditions, the bound water is removed from the unit cell and the Form II crystal is formed.

The difference between the small angle regions of Figures 3 and 6 is consistent with the above speculation on the formation mechanism of the Form II crystal. The PPTA/ $\mathrm{H}_{2} \mathrm{SO}_{4}$ complex crystals are fairly perfect, with negligible scattering in the small angle region (Figure 3). The strong SAXS of PPTA/ $\mathrm{H}_{2} \mathrm{O}$ spherulites (Figure 6) indicates that many micro-cavities exist in fibrils of PPTA/ $\mathrm{H}_{2} \mathrm{O}$ spherulites. These cavities are formed during the hydrolysis process of PPTA/ $\mathrm{H}_{2} \mathrm{SO}_{4}$ complex crystals.

Acknowledgments. The authors are indebted to Professor R. Qian of the Institute of Chemistry, The Chinese Academy of Sciences, for his valuable suggestions and comments. We express our appreciation to the Japan Society for the Promotion of Science and the Chinese Academy of Sciences for their financial support to one of us (D. X.). 


\section{REFERENCES}

1. M. M. Iovleva, S. I. Banduryan, and S. P. Papkov, Vysokomol. Soedin. Ser. B, 21, 351 (1979).

2. T. Takahashi, H. Iwamoto, $\mathrm{K}$. Inoue, and I. Tsujimoto, J. Polym. Sci. Polym. Phys. Ed., 17, 115 (1979).

3. S. Chen and C. Long, Gaofenzi Tongxun (Polym. Commun., China), 240 (1979).

4. H. Aoki, Y. Onogi, J. L. White, and J. F. Fellers, Polym. Eng. Sci., 20, 221 (1980).

5. Y. Onogi, J. L. White, and J. F. Fellers, J. Polym. Sci., Polym. Phys. Ed., 18, 663 (1980).

6. M. Arpin, C. Strazielle, and A. Skoulios, J. Phys., 38 307 (1977).

7. D. $\mathrm{Xu}, \mathrm{K}$. Okuyama, F. Kumamaru, M. Takayanagi, S. Zhang, and R. Qian, J. Polym. Sci., Polym. Lett. Ed., 20, 159 (1982).

8. V. G. Kulichikhin, V. A. Platonov, Ye, G. Kgan, L. P. Mil'kova, I. N. Andreyeva, N. V. Lukasheva, A. V. Volokhina, and S. P. Papkov, Vysokomol. Soedin.
Ser. A, 20, 2224 (1978).

9. S. Chen, Gaofenzi Tongxun (Polym. Commun., China), 1 (1979).

10. H. G. Weyland, Polym. Bull., 3, 331 (1980).

11. B. Jingsheng, Y. Anji, Z. Shengging, Z. Shufan, and H. Chang, J. Appl. Polym. Sci., 26, 1211 (1981).

12. D. Xu and S. Zhang, unpublished data.

13. K. Haraguchi, T. Kajiyama, and M. Takayanagi, $J$. Appl. Polym. Sci., 23, 915 (1979).

14. M. G. Northolt, Eur. Polym. J., 10, 799 (1977).

15. R. Hasegawa, Y. Chatani, and H. Tadokoro, Abstract, Meeting of the Society of Crystallography Japan, Osaka, Japan, 1973, p 21.

16. R. D. B. Fraser, T. P. MacRae, and E. Suzuki, J. Appl. Crystallogr., 11, 693 (1978).

17. T. A. Hancock, J. E. Spruiel, and J. L. White, J. Appl. Polym. Sci., 21, 1227 (1977).

18. P. J. C. Smith and S. Arnott, Acta Crystallogr. Sect. A, 34, 3 (1978).

19. C. K. Johnson, Report ORNL-5138, Oak Ridge National Laboratory, Oak Ridge, Tenn., 1976. 